\title{
Examining the Effectiveness of Gamification in Mental Health Apps for Depression: Systematic Review and Meta-analysis
}

Stephanie G Six ${ }^{1}$, BA; Kaileigh A Byrne ${ }^{1}, \mathrm{PhD}$; Thomas P Tibbett ${ }^{2}$, PhD; Irene Pericot-Valverde ${ }^{3}, \mathrm{PhD}$

${ }^{1}$ Department of Psychology, Clemson University, Clemson, SC, United States

${ }^{2}$ SAP National Security Services, Inc, Newtown Square, PA, United States

${ }^{3}$ Clemson University School of Health Research, Greenville, SC, United States

\author{
Corresponding Author: \\ Kaileigh A Byrne, PhD \\ Department of Psychology \\ Clemson University \\ 418 Brackett Hall \\ Clemson, SC, 29634 \\ United States \\ Phone: 18646563935 \\ Email: kaileib@clemson.edu
}

\section{Abstract}

Background: Previous research showed that computerized cognitive behavioral therapy can effectively reduce depressive symptoms. Some mental health apps incorporate gamification into their app design, yet it is unclear whether features differ in their effectiveness to reduce depressive symptoms over and above mental health apps without gamification.

Objective: The aim of this study was to determine whether mental health apps with gamification elements differ in their effectiveness to reduce depressive symptoms when compared to those that lack these elements.

Methods: A meta-analysis of studies that examined the effect of app-based therapy, including cognitive behavioral therapy, acceptance and commitment therapy, and mindfulness, on depressive symptoms was performed. A total of 5597 articles were identified via five databases. After screening, 38 studies ( $n=8110$ participants) remained for data extraction. From these studies, 50 total comparisons between postintervention mental health app intervention groups and control groups were included in the meta-analysis.

Results: A random effects model was performed to examine the effect of mental health apps on depressive symptoms compared to controls. The number of gamification elements within the apps was included as a moderator. Results indicated a small to moderate effect size across all mental health apps in which the mental health app intervention effectively reduced depressive symptoms compared to controls (Hedges $\mathrm{g}=-0.27,95 \% \mathrm{CI}-0.36$ to $-0.17 ; P<.001$ ). The gamification moderator was not a significant predictor of depressive symptoms $(\beta=-0.03, \mathrm{SE}=0.03 ; P=.38)$, demonstrating no significant difference in effectiveness between mental health apps with and without gamification features. A separate meta-regression also did not show an effect of gamification elements on intervention adherence $(\beta=-1.93, \mathrm{SE}=2.28 ; P=.40)$.

Conclusions: The results show that both mental health apps with and without gamification elements were effective in reducing depressive symptoms. There was no significant difference in the effectiveness of mental health apps with gamification elements on depressive symptoms or adherence. This research has important clinical implications for understanding how gamification elements influence the effectiveness of mental health apps on depressive symptoms.

(JMIR Ment Health 2021;8(11):e32199) doi: $\underline{10.2196 / 32199}$

\section{KEYWORDS}

depression; reward; gamification; mental health apps; apps

\section{Introduction}

Depression is a highly prevalent mental disorder in the United States that affects 17.3 million people [1]. Effective treatments are available to treat depression, including pharmacotherapy and psychological treatment [2,3]. However, widespread barriers to treatment exist, such as problems of consistent adherence, access to mental health care resources, and cost [4-7]. The 
United States alone spends approximately US \$71 billion annually on depression treatment [8], which underscores the substantial financial burden that depression can incur. Furthermore, of all adult Americans who experienced a major depressive episode in $2017,35 \%$ did not receive treatment [1].

To mitigate these challenges, companies have created technology-based mental health apps, with the goal of alleviating symptoms of various mental disorders [8,9]. As of 2019, $81 \%$ of all Americans owned a smartphone, which highlights the potential impact of technology-based mental health apps: providing a platform, consuming less time, requiring less commitment, and allowing users to move at their own pace [10]. This ubiquity suggests that app technology could make treatment more accessible by providing individuals with cost-efficient tools and apps to aid them between sessions. However, development of these apps is recent and additional attention is needed to identify what is most effective and rewarding about these digital tool kits.

People with depression frequently experience anhedonia, which may result in blunted sensitivity to reward [11-15]. Depressed individuals view rewards, like money or social encouragement, as less motivating than individuals without depressive symptoms [16-18]. Effective therapeutic approaches may benefit from improving this reward-processing deficit, potentially through the use of gamification elements. Gamification is defined as the use of game-design elements and incentives combined with desired behaviors in order to positively influence user motivation, behavior of users, and adherence [19-22]. Previous research suggests that different gamification elements represent motivational affordances that can influence psychological outcomes [23]. These elements include leaderboards, achievements, badges, levels, challenges, and points [23]. The Unified Gamification and Motivation (UGM) model lends a framework for understanding how including gamification elements in therapeutic intervention can enhance treatment engagement [24]. Based on this model, the inclusion of game-like elements would make the intervention more salient, which could increase motivation to use the intervention, thereby resulting in greater treatment usage.

Much of the work demonstrating the effects of gamification elements on reward motivation stems from video game research. For example, in a recent study, young adults were randomized to either a video game training or a control task [25]. After 2 months playing the video game, participants randomized to the video game intervention exhibited higher activation in the ventral striatum (ie, increase in reward activation) during a nongamified task than those assigned to the control task at 2 months posttest. This finding suggests that (1) the effect of video games on reward motivation can transfer to other tasks and (2) video games can enhance individuals' general reward responsiveness to positive stimuli [25]. However, very little research has centered on how individuals suffering from depression are motivated to pursue reward and engage in video games. The capability of video games to enhance reward processing, motivation, and engagement could play a critical role in the development of app technology specifically grappling with anhedonia.
Mental health apps provide a potential way to reduce symptoms and increase adherence by dispensing psychoeducation and other therapeutic skills through an electronic, easily accessible format [26-34]. Some apps include reward-based features, in the form of money, games, or hearts (eg, SPARX-R) [35], while other apps do not mention any type of reward (eg, AI Tess) [36]. Yet, these apps appear effective overall; in an initial meta-analysis collecting data from nine randomized controlled trials (RCTs) with depression as a secondary concern (mean age 36.1 years; male, $34.8 \%$ ), results indicated that mental health apps led to a large reduction in depressive symptoms [30]. A second meta-analysis (19 RCTs; mean age 30.7 years; female, $63.17 \%$ ) examined the effect of smartphone mental health apps on a variety of disorders (eg, anxiety, substance use, and sleep problems) including depression, and results showed significant differences between groups in reducing depressive symptoms with a small to moderate effect size [37]. Another meta-analysis, which predominately recruited adults over the age of 16 years (93.3\%), examined 45 RCTs with various technological interventions for depressive patients, like symptom tracking, online diaries, and email and phone reminders. Depressive symptoms showed significant reductions in comparison to either wait-list or treatment-as-usual controls [38]. Taken together, there is evidence that mental health apps are effective, but the variability in effect size between meta-analyses suggest there could be another mechanism. Given the UGM model, gamification is a logical next step to replicate prior meta-analyses and add further context. Mental health apps offer a novel, easily accessible way to combine therapy techniques and motivational reward elements, like a video game, yet it is unclear whether reward or gamification features uniquely offer additional advantages in reducing depressive symptoms. Pairing this novel app approach with traditional techniques that are effective for depression may be able to mitigate anhedonia symptoms.

The purpose of this systematic review and meta-analysis is to (1) provide a comprehensive and updated meta-analytical evaluation of the effectiveness of mental health apps in reducing depressive symptoms and (2) to assess whether mental health apps with gamification elements are more effective than those without. Prior research on video games, like apps, indicates high levels of reward motivation and pleasure [25,39]. Additionally, previous systematic reviews and meta-analyses have shown significant reductions in symptoms for depression and other mental disorders while using mental health apps, some of which included cognitive behavioral therapy (CBT) or gamification elements $[26,36,37,40,41]$. However, no study to date has explored the effectiveness of mental health apps with gamification components in mitigating depressive symptoms.

Previous research shows that gamification can increase motivation to engage with mental health apps [42-44], improve mood [45], and activate the ventral striatum, which can enhance individuals' general reward responsiveness to positive stimuli [21]. Building on this research, we propose that gamification may enhance the efficacy of therapeutic-based apps (eg, CBT) and reduce depressive symptoms through the following mechanism: (1) it might increase engagement with and adherence to mental health apps and (2) it may activate 
reward-mediated neural pathways, eliciting positive feelings, which might counteract some negative feelings from depression. We hypothesize that mental health apps that include gamification elements will be more effective in reducing depressive symptoms and increasing adherence than those without such elements.

\section{Methods}

\section{Overview}

The systematic review and meta-analysis were conducted following the PRISMA (Preferred Reporting Items for Systematic Reviews and Meta-Analyses) guidelines [46]. A protocol was designed and registered through the Open Science Framework after data collection and before data extraction and analysis began [47]. The quality of the studies included was assessed through the Cochrane Collaboration's risk of bias assessment tool [48].

\section{Eligibility and Inclusion Criteria}

Studies were included if they met the following criteria: (1) studies involving human participants; (2) mental health apps targeting depression as a primary, secondary, or tertiary outcome; (3) RCTs or experimental or quasi-experimental designs with an active, wait-list, or treatment-as-usual control group; (4) published between January 1, 2005, and December 31, 2020; (5) mental health app intervention groups contain elements of CBT, acceptance and commitment therapy (ACT), behavioral activation (BA), or mindfulness; and (6) provide a measure of depressive symptoms pre- and posttreatment. Studies were excluded if they (1) were books chapters, meta-analyses, reviews, case studies, or opinion pieces; (2) were not written in English; (3) included participants younger than 18 years of age; (4) included participants with a terminal or life-threatening illness (eg, patients with cancer who had depression) to avoid potential confounds of disentangling which condition (ie, life-threatening illness or depression) influenced outcomes; and (5) included a therapist or other mental health specialist's guidance for the mental health apps, as this could create a confound. No specific measure of depression was required, in order to allow the focus to remain on the mental health apps.

\section{Literature Search Strategy}

Studies were identified through a comprehensive literature search in PubMed, PsycInfo, Cochrane Clinical Trials Registry, Web of Science, and PsyArXiv (for publication bias) with no publication date restriction. The search was conducted in February 2021. Additionally, the authors conducted a manual search to locate studies that were not identified through databases. Search terms used three different concepts critical to the extant literature: app-based, mental health, and reward or gamification. Within each concept (eg, app-based), we identified multiple tags that reflected this concept (eg, "mental health app" and "MHapp"). The specific combination of operators can be found in Multimedia Appendix 1. This resulted in 129 unique combinations of search terms (eg, "MHapp-Money" and "Depression-Points").

\section{Study Selection Procedure}

During the identification phase, articles were identified and collected based on the search term combinations from the five databases. After duplicate removal, two researchers (SGS and $\mathrm{KAB}$ ) independently conducted initial screening for eligible articles by assessing titles and abstracts for inclusion or exclusion criteria (Multimedia Appendix 2). After the initial screening, both researchers independently assessed the remaining full-text articles against the inclusion and exclusion criteria. Disagreements were resolved through re-examination of the articles in question and discussion among the screeners.

\section{Data Extraction}

Two independent reviewers independently coded the studies in a Microsoft Excel spreadsheet. The following data were extracted from each article: first author, year of publication, participants' characteristics (ie, gender and age), population, and study length (Multimedia Appendix 3), as well as app name, app classification (ie, mobile or internet), presence of gamification elements, type of gamification element (eg, digital rewards, challenge or game, and competition or challenges), app adherence, the instrument used to measure depression, and type of therapy (eg, CBT and ACT) offered (Table 1) [31,49-85]. 
Table 1. Study app classification, therapy, and gamification information.

\begin{tabular}{|c|c|c|c|c|c|}
\hline First author, publication year, and app & App classification & Depression measure & Therapy intervention & Game elements, $\mathrm{n}$ & Adherence rate, $\%$ \\
\hline \multicolumn{6}{|l|}{ Bakker, 2018 [54] } \\
\hline MoodMission & Mobile & PHQ-9 ${ }^{\mathrm{a}}$ & $\mathrm{CBT}^{\mathrm{b}}$ & 2 & 69.6 \\
\hline MoodPrism & Mobile & PHQ-9 & CBT & 2 & 46.4 \\
\hline MoodKit & Mobile & PHQ-9 & CBT & 0 & 46.0 \\
\hline \multicolumn{6}{|l|}{ Berger, 2011 [85] } \\
\hline Deprexis & Mobile & BDI-II ${ }^{\mathrm{c}}$ & $\begin{array}{l}\mathrm{BA}^{\mathrm{d}}, \mathrm{PST}^{\mathrm{e}} \text {, and mind- } \\
\text { fulness }\end{array}$ & 1 & $N / A^{f}$ \\
\hline \multicolumn{6}{|l|}{ Birney, 2016 [80] } \\
\hline Moodhacker & Internet & PHQ-9 & Mindfulness & 0 & N/A \\
\hline \multicolumn{6}{|l|}{ Bosso, 2020 [67] } \\
\hline Headspace & Mobile & DASS- $21^{\mathrm{g}}$ & Mindfulness & 3 & 58.0 \\
\hline \multicolumn{6}{|l|}{ Bostock, 2019 [68] } \\
\hline Headspace & Mobile & HADS $^{\mathrm{h}}$ & Mindfulness & 3 & 2.0 \\
\hline \multicolumn{6}{|l|}{ Botella, 2016 [57] } \\
\hline Smiling is Fun & Internet & BDI-II & CBT & 1 & 86.4 \\
\hline \multicolumn{6}{|l|}{ Choi, 2012 [81] } \\
\hline Brighten Your Mood & Internet & $\mathrm{CBDI}^{\mathrm{i}}$ & CBT & 0 & 68.0 \\
\hline \multicolumn{6}{|l|}{ Collins, 2018 [51] } \\
\hline MindWise & Internet & PHQ-9 & CBT & 0 & 41.7 \\
\hline \multicolumn{6}{|l|}{ Dahne, 2019 [66] } \\
\hline Aptivate & Mobile & BDI-II & CBT & 2 & 36.4 \\
\hline iCouch CBT & Mobile & BDI-II & CBT & 0 & N/A \\
\hline \multicolumn{6}{|l|}{ Dahne, 2019 [77] } \\
\hline Moodivate & Mobile & BDI-II & CBT & 2 & 42.9 \\
\hline Moodkit & Mobile & BDI-II & BA & 0 & N/A \\
\hline \multicolumn{6}{|l|}{ Deady, 2020 [78] } \\
\hline HeadGear & Internet & PHQ-9 & BA and mindfulness & 2 & 10.1 \\
\hline \multicolumn{6}{|l|}{ de Graaf, 2009 [62] } \\
\hline Colour Your Life & Internet & BDI-II & CBT & 0 & 36.0 \\
\hline \multicolumn{6}{|l|}{ Fish, 2019 [53] } \\
\hline Headspace & Mobile & PHQ-9 & Mindfulness & 3 & N/A \\
\hline \multicolumn{6}{|l|}{ Flett, 2018 [69] } \\
\hline Headspace & Mobile & CES-D ${ }^{\mathrm{j}}$ & Mindfulness & 3 & 16.4 \\
\hline Smiling Mind & Mobile & CES-D & Mindfulness & 1 & 15.4 \\
\hline Evernote & Mobile & CES-D & N/A & 0 & N/A \\
\hline \multicolumn{6}{|l|}{ Fuller-Tyszkiewicz, 2020 [73] } \\
\hline StressLess & Mobile & DASS-21 & $\begin{array}{l}\text { Mindfulness-based } \\
\text { CBT }\end{array}$ & 1 & 19.0 \\
\hline Stress Monitor & Mobile & DASS-21 & N/A & 1 & N/A \\
\hline \multicolumn{6}{|l|}{ Gilbody, 2015 [63] } \\
\hline Beating the Blues & Internet & PHQ-9 & CBT & 0 & 79.0 \\
\hline
\end{tabular}




\begin{tabular}{|c|c|c|c|c|c|}
\hline First author, publication year, and app & App classification & Depression measure & Therapy intervention & Game elements, $n$ & Adherence rate, $\%$ \\
\hline MoodGYM & Internet & PHQ-9 & CBT & 2 & 75.0 \\
\hline
\end{tabular}

Ha, 2020 [49]

Spring

Howells, 2016 [56]

Headspace

Catch Notes

Hur, 2018 [72]

Todac Todac

Kladnitski, 2020 [71]

$\mathrm{iCBT}^{\mathrm{k}}$ program
$\mathrm{MEiCBT}^{\mathrm{l}}$ program
$\mathrm{iMT}^{\mathrm{m}}$ program

Krafft, 2019 [58]

Simple Matrix

Stop, Breathe, \& Think

Internet

Lintvedt, 2013 [79]

MoodGYM
Blue Pages

Löbner, 2018 [64]

$$
\text { MoodGYM }
$$

Lokman, 2017 [60]

CDMIs $^{\mathrm{p}}$ : Sleep Better, Worry

Less, and Stress Less

Lüdtke, 2018 [59]

Be Good to Yourself

Mobile

Mobile

Internet

Mobile

Internet

Mobile

Internet

Internet

Internet

Internet

Internet

Internet

Richards, 2020 [55]

Space from Depression

Richards, 2015 [83]

Space from Depression

Roepke, 2015 [31]

SuperBetter
Complex Matrix

Levin, 2020 [75]

BDI-II

CES-D

CES-D

BDI-II

PHQ-9

PHQ-9

PHQ-9

DASS-21

DASS-21

CCAPS- $34^{\circ}$

Mindfulness

0

CES-D

CES-D

CBT

N/A

N/A

CBT

IDS-SR $^{\mathrm{q}}$

CBT

N/A

PHQ-9

CBT

3

79.6

BDI-II

CBT

6

40.7

HADS

CBT and mindfulness 2

7.0

DASS-21

CBT and mindfulness 3

N/A

BDI-II

CBT

Rollman, 2018 [84] 


\begin{tabular}{|c|c|c|c|c|c|}
\hline First author, publication year, and app & App classification & Depression measure & Therapy intervention & Game elements, $n$ & Adherence rate, $\%$ \\
\hline Beating the Blues & Internet & PROMIS $^{r}$ & CBT & 0 & 85.8 \\
\hline \multicolumn{6}{|l|}{ Schure, 2019 [76] } \\
\hline Thrive & Mobile & PHQ-9 & CBT & 3 & 58.6 \\
\hline \multicolumn{6}{|l|}{ Sethi, 2013 [65] } \\
\hline MoodGYM & Mobile & DASS-21 & CBT & 2 & N/A \\
\hline \multicolumn{6}{|l|}{ Tighe, 2017 [74] } \\
\hline ibobbly & Mobile & PHQ-9 & Mindfulness and ACT & 0 & 85.0 \\
\hline \multicolumn{6}{|l|}{ Twomey, 2014 [50] } \\
\hline MoodGYM & Internet & DASS-21 & CBT & 2 & 27.3 \\
\hline
\end{tabular}

aPHQ-9: 9-item Patient Health Questionnaire.

${ }^{\mathrm{b}} \mathrm{CBT}$ : cognitive behavioral therapy.

${ }^{\mathrm{c}}$ BDI-II: Beck Depression Inventory-II.

${ }^{\mathrm{d}} \mathrm{BA}$ : behavioral activation.

ePST: problem-solving therapy.

${ }^{f}$ N/A: not applicable; values were not reported.

gDSS-21: 21-item Depression, Anxiety, and Stress Scale.

${ }^{\mathrm{h}}$ HADS: Hospital Anxiety and Depression Scale.

${ }^{\mathrm{i}}$ CBDI: Chinese version of the Beck Depression Inventory.

${ }^{\mathrm{j}}$ CES-D: Center for Epidemiological Studies Depression Scale.

$\mathrm{k}_{\mathrm{iCBT}}$ : internet-delivered cognitive behavioral therapy.

${ }^{1}$ MEiCBT: mindfulness-enhanced internet-delivered cognitive behavioral therapy.

$\mathrm{m}_{\mathrm{iMT}}$ : internet-delivered mindfulness training.

${ }^{\mathrm{n}}$ ACT: acceptance and commitment therapy.

${ }^{\circ}$ CCAPS-34: Counseling Center Assessment of Psychological Symptoms-34.

PCDMI: complaint-directed mini-intervention.

qIDS-SR: Inventory of Depressive Symptomatology Self-Report.

${ }^{\mathrm{r}}$ PROMIS: Patient-Reported Outcomes Measurement Information System.

The conceptualization of gamification was modeled after previous research in which gamification was defined as having three components: a design feature that uses motivational affordances to influence psychological and behavioral outcomes [23]. Another literature review that focused exclusively on the health and well-being app domain has described very similar conceptualizations of gamification elements [86]. Modeled after these gamification literature reviews, gamification for this meta-analysis was defined using the following nine motivational affordance categories: points, achievements or badges, levels, narrative stories or themes, clear goals, performance-based feedback, rewards, progress metrics (eg, progress bars), and challenges $[23,86]$. While gamification can also include leaderboards [19], this element was excluded from the meta-analysis, as leaderboards in the context of mental health may promote social comparison, which can be counterproductive $[87,88]$. First authors of the studies were contacted via email to confirm conceptualization of the number of gamification elements. The number of gamification elements included in each intervention was included as a moderator in analyses.
Raw depression scores (mean and SD) at posttreatment for each study were extracted. If a study compared more than one mental health app intervention to a control group, or if more than one independent sample was examined in an article, both were included as separate comparisons. Studies used different, but convergently valid, measures of depression. If the articles met any of the exclusion criteria, specifically missing data, they were excluded from data analysis $(n=12)$.

\section{Quality Assessment}

The quality of each study was assessed using the Cochrane Collaboration's risk of bias assessment tool, which provided seven basic criteria: random sequence generation, allocation concealment, blinding of participants and personnel, blinding of outcome assessment, incomplete outcome data, selective reporting, and other biases [48]. Studies were scored on a scale ranging from 0 to 2 , where 0 indicates "low or no bias," 1 indicates that the "level of bias is unclear," and 2 indicates "high bias" (Multimedia Appendix 4). In line with previous research, if a study did not address one of the categories, it was given a 1 for the lack of explanation [89]. Total scores for individual and all studies are presented in Figure 1. 
Figure 1. Risk of bias across all studies included in the meta-analysis based on the Cochrane Collaboration's risk of bias assessment tool.

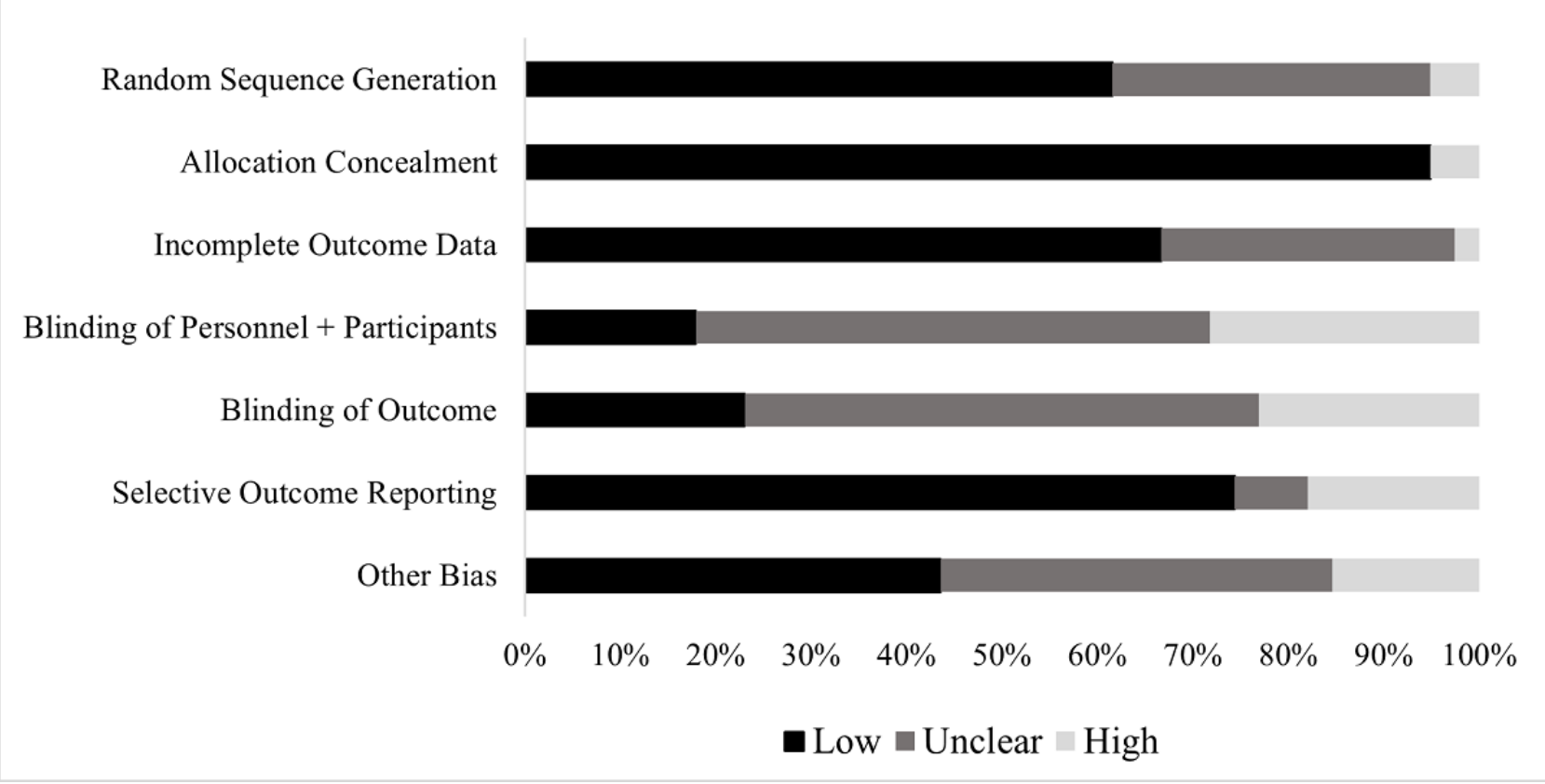

\section{Data Analysis}

\section{Overview}

The resulting depression questionnaires included in the analyzed studies were as follows: the 9-item Patient Health Questionnaire (PHQ-9) [90]; the Beck Depression Inventory-II (BDI-II) [91]; the Center for Epidemiological Studies Depression Scale (CES-D) [92]; the depression subscale of the 21-item Depression, Anxiety, and Stress Scale (DASS-21) [93]; the Hospital Anxiety and Depression Scale (HADS) [94]; the Inventory of Depressive Symptomatology Self-Report (IDS-SR) [95]; the depression scale from the Counseling Center Assessment of Psychological Symptoms-34 (CCAPS-34) [96]; and the depression scale from the Patient-Reported Outcomes Measurement Information System (PROMIS). All questionnaires involved a 4-point scale, ranging from 0 (very low levels of depressive symptoms) to 3 (very high levels of depressive symptoms). Some studies reported sum scores, while others reported average scores. To ensure that all questionnaire data were comparable along the same scale, average depression scores were computed for analysis.

The meta-analytic data were analyzed in RStudio, primarily using the meta (version 4.18) and metafor (version 3.0) packages in $\mathrm{R}$ (version 3.6.3; The R Foundation) to determine effect size and between-group differences. Means and variances were aggregated for studies that included two primary measures of depression to compute a single comparison [97]. This led to a total of 50 comparisons in the meta-analysis. From this data, the pooled SD, $t$ test value, $\mathrm{P}$ value, degrees of freedom, SE, and Hedges $g$ were calculated. The Hedges $g$ effect size provides an index of the magnitude of the difference between two means and corrects for potential biases in small samples [97,98]. The bias correction was performed using the following formula: $\frac{n-3}{n-2.25}\left(\sqrt{\frac{n-2}{n}}\right)$ where $\mathrm{n}=\mathrm{n}_{1}+\mathrm{n}_{2}$ [99]. An effect size of 0.2 represents a small effect size, 0.5 reflects a moderate effect size, and $\geq 0.80$ represents a large effect size $[98,100]$.
Following previous meta-analyses comparing intervention effects on depressive symptoms [26,37,41], the effectiveness of mental health apps was assessed using one outcome: difference in depressive symptoms between intervention and control groups at posttreatment. To test the hypothesis that mental health apps would be effective in reducing depressive symptoms, a random effects model was used to examine differences in the magnitude of depressive symptomology between those mental health app interventions compared to control conditions. The continuous variable of number of gamification elements was included in the random effects model as a moderator to test whether gamification elements influenced the effectiveness of mental health apps. The duration of the intervention, in months, was also included as a moderator variable. The $\mathrm{I}^{2}$ statistic was computed to determine heterogeneity across studies: an $\mathrm{I}^{2}$ value of $\leq 25 \%$ suggests low heterogeneity, $\sim 50 \%$ suggests moderate heterogeneity, and $\geq 75 \%$ suggests high heterogeneity across studies [101]. While some articles provided follow-up time point data, only data from the postintervention period or data that were specified as the primary endpoint were analyzed in the primary meta-analysis.

\section{Subgroup and Sensitivity Analyses}

A sensitivity analysis using a random effects model with the gamification moderator was conducted to examine the effectiveness of mental health apps on depressive symptoms among the CBT-based apps that excluded ACT and mindfulness-based interventions. A secondary meta-regression analysis with the gamification moderator was performed for studies that included a measure of adherence rates (ie, percentage completion of all intervention modules or requirements) for the intervention condition. The adherence analysis included 28 studies with 37 comparisons. 


\section{Assessment of Publication Bias}

A funnel plot was created to provide a visual of potential bias. The vertical line indicates the estimated effect of all studies. Pseudo-CIs were generated around this line in homogenous data sets to indicate $95 \% \mathrm{CI}$ boundaries. Asymmetrical funnel plots suggest that the effects of an intervention in studies with small sample sizes are different - typically more impactful-than in studies with larger sample sizes and may indicate publication bias [102]. However, if model estimates suggest heterogeneity, a transformation manipulates these pseudo-CIs to take the heterogeneity into account: $\pm 1.96 \times \sqrt{ }\left(\mathrm{SE}^{2}+\tau^{2}\right)$ where the $\tau^{2}$ variable indicates the degree of heterogeneity. Its inclusion in the pseudo-CI calculation results in two curved lines asymptotic to the original estimated effect, a broader and wider funnel more inclusive of variance.

The presence of publication bias was also measured with the Egger test and the trim-and-fill approach by Duval and Tweedie. The Egger test [103] was performed to quantify whether there was significant small-study publication bias in the included studies. The trim-and-fill analysis by Duval and Tweedie was conducted to establish an unbiased estimate of the pooled effect size by correcting for funnel plot asymmetry due to publication bias [104]. Significant findings indicate whether the study sample is asymmetrical or "missing" publications that would positively or negatively bias the estimate.

\section{Results}

\section{Results of the Review}

Data collection commenced in February 2021 and ended in May 2021. As of June 2021, a total of 5597 articles were identified through the literature search. After duplicate removal, 2741 eligible articles remained for title and abstract screening. Two researchers (SGS and KAB) independently identified 101 articles as potentially eligible. Screeners had an agreement rate of $98.94 \%$ (Cohen $k=0.85$ ). Full-text screening of these 101 articles was conducted. Of the reviewed articles, 38 studies with 39 different mental health apps met the inclusion criteria and were therefore included. Figure 2 presents the study selection identification, screening, and eligibility process. 
Figure 2. PRISMA (Preferred Reporting Items for Systematic Reviews and Meta-Analyses) flow diagram of the studies included in the systematic review and meta-analysis. ACT: acceptance and commitment therapy; CBT: cognitive behavioral therapy.
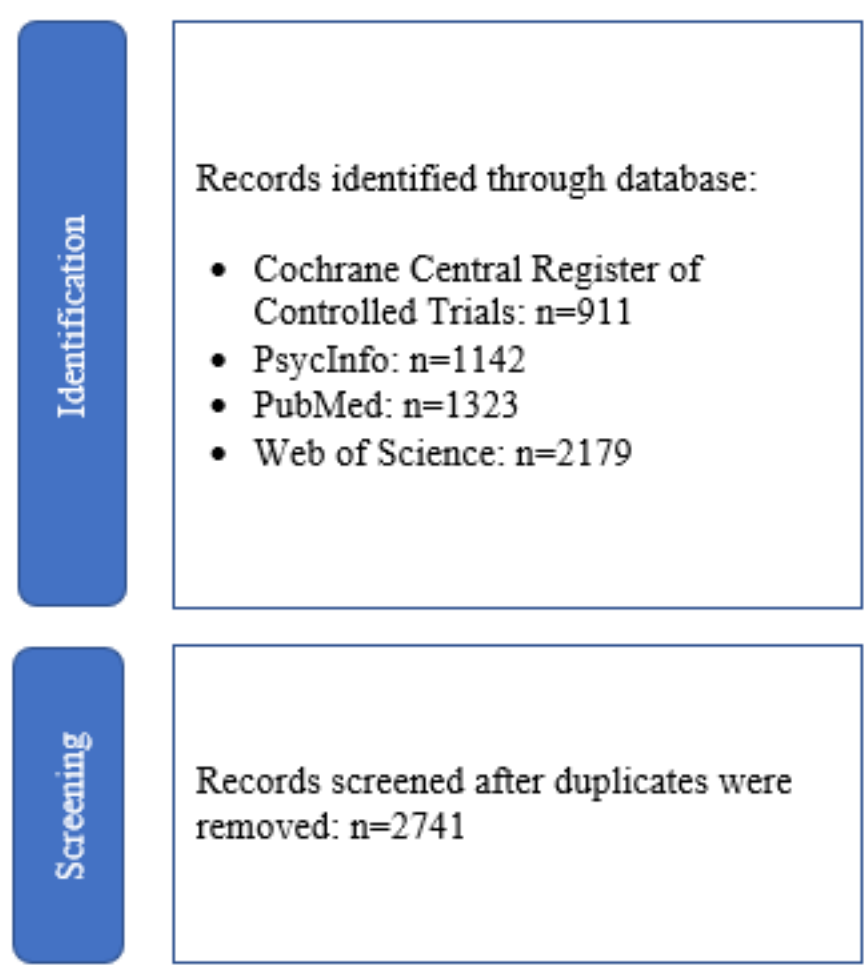

Records screened after duplicates were removed: $\mathrm{n}=2741$

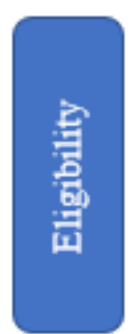

Full-text articles assessed for eligibility: $\mathrm{n}=101$

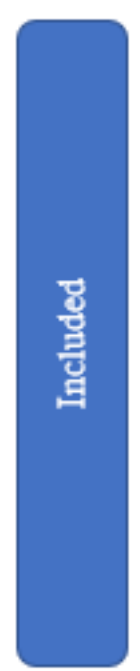

Records included in quantitative synthesis (meta-analysis)

$\mathrm{N}=38$ studies

\section{Participant and Study Characteristics}

A total of 8110 participants provided analyzable data (4362, $53.8 \%$, in the interventions and $3748,46.2 \%$, in the control conditions) for this meta-analysis, with the majority of participants being female $(\mathrm{n}=4728,58.3 \%$; mean age 35.6, SD 7.9, years). Multimedia Appendix 3 shows descriptive information for each study. Treatment duration ranged from 10
Additional records identified through other sources: $\mathrm{n}=54$

Records excluded based on title and abstract: $n=2640$

Excluded articles: $n=63$

Primary exclusion reason:

- Active assistance from therapists: $n=7$

- Lacking data: $n=12$

- Not related to the research question: $n=5$

- Not therapy for depression: $n=3$

- Participants younger than 18 years: $n=1$

- Not CBT, $A C T$, or mindfulness: $n=3$

- Lacking a true control group: $\mathrm{n}=3$

- Apps specific to a certain population or mental disorder other than depression: $\mathrm{n}=11$

- Just a manual: $n=9$

- Neither internet nor app-based: $n=1$

- Published before 2005: $\mathrm{n}=1$

- Duplicates: $\mathrm{n}=7$ days to 4 months. Most of the studies $(26 / 38,68 \%)$ used mental h e a l t h a p p s w t h $\quad$ C B T $[31,45-48,50,51,53,55-62,66-68,72-75,77-79], 32 \% \quad(12 / 38)$ used mindfulness [49,52,57,63-67,69-71,74,76,82], 8\% (3/38) used ACT [62,73,82], 8\% (3/38) did not have a therapy associated with the app, and only 5\% (2/38) used BA [54,70]. In terms of the depressive symptom outcome measures, $32 \%$ $(12 / 38)$ of the studies used the PHQ-9, 26\% (10/38) used the 
BDI-II, 16\% (6/38) used the DASS-21, 11\% (4/38) used the CES-D, 3\% (1/38) used the HADS, 3\% (1/38) used the IDS-SR, $3 \%(1 / 38)$ used the CCAPS-34, and $3 \%(1 / 38)$ used the PROMIS.

Of the 50 different comparisons used in the 38 different studies, $71 \%(27 / 38)$ contained gamification elements and 29\% (11/38) did not. The number of gamification elements observed in each study are shown in Multimedia Appendix 5. Table 1 shows the type of intervention, app, and number of gamification elements for each article. Multimedia Appendix 6 reports supplemental meta-analytic results for long-term follow-up time points and control variables.

\section{Primary Analysis}

A forest plot for the postintervention differences between the mental health app intervention group and the control group is shown in Figure 3. The random effects model for all eligible studies ( $n=50$ comparisons) revealed a small to medium effect of mental health apps in reducing depressive symptoms compared to controls ( $\mathrm{g}=-0.27,95 \% \mathrm{CI}-0.36$ to $-0.17 ; \mathrm{P}<.001)$. However, significant heterogeneity in the results were observed $\left(\mathrm{I}^{2}=0.76, \tau^{2}=0.076 ; \mathrm{P}<.001\right)$. The gamification moderator was not a significant predictor of depressive symptoms $(\beta=-0.03$, $\mathrm{SE}=0.04 ; \mathrm{P}=.38)$; the intervention duration moderator was also not a significant predictor $(\beta=-0.02, \mathrm{SE}=0.04 ; \mathrm{P}=.67)$.

Figure 3. Forest plot for all studies ( $\mathrm{n}=50$ comparisons) showing the effect sizes for each. Author and year for each study are listed on the $y$-axis.

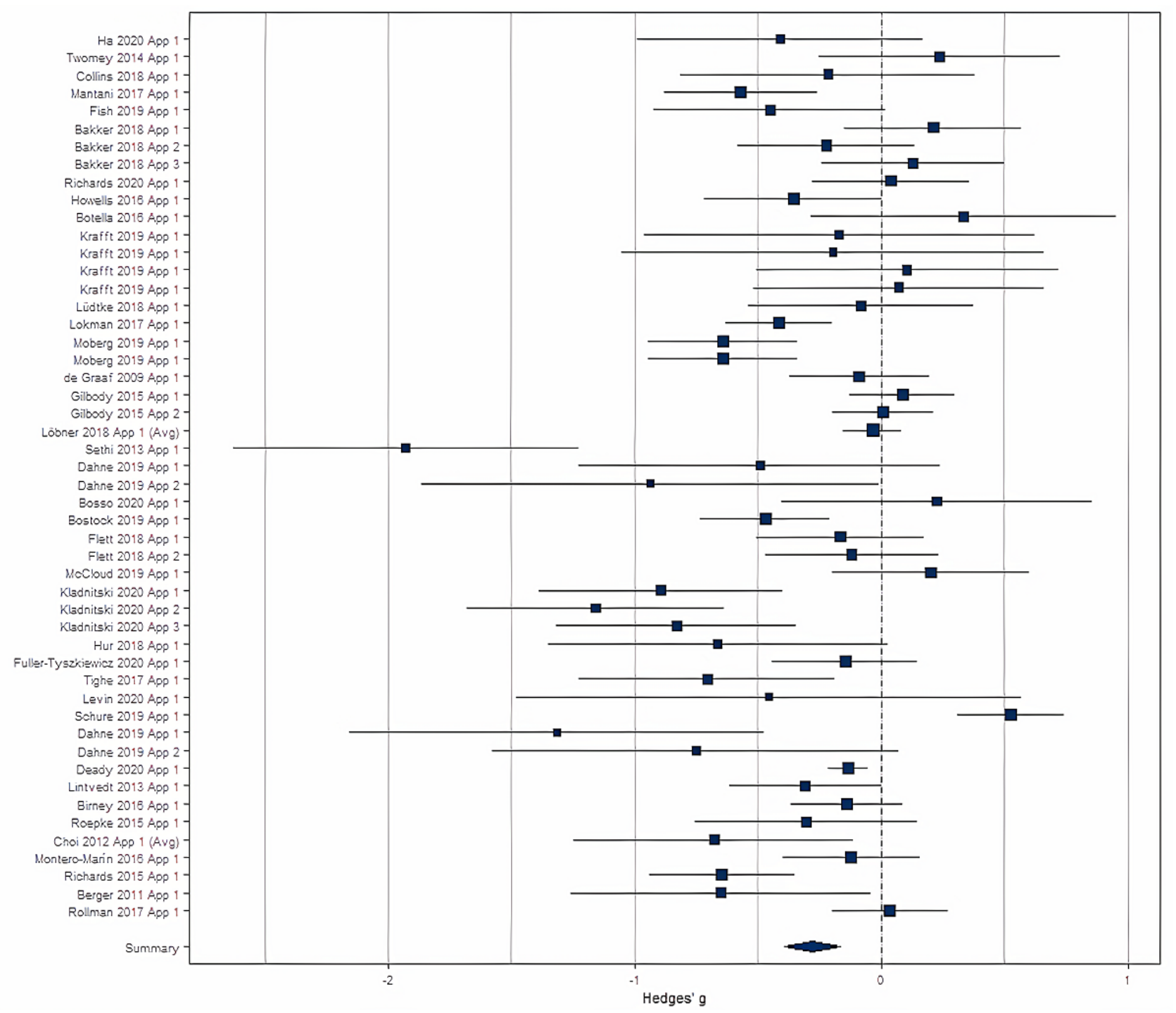

\section{Sensitivity Analysis: CBT-Only Studies}

A sensitivity analysis was performed for app comparisons that involved CBT-based therapy $(37 / 50,74 \%)$. The overall effect size was similar to the overall analysis $(\mathrm{g}=-0.30,95 \% \mathrm{CI}-0.42$ to $-0.17 ; \mathrm{P}<.001)$, and there was no significant effect of gamification elements as a moderator $(\beta=-0.04, \mathrm{SE}=0.04 ; \mathrm{P}=.31)$ or of study duration as a moderator $(\beta=-0.02, \mathrm{SE}=0.05 ; \mathrm{P}=.69)$. Multimedia Appendix 7 show the funnel plot for this analysis.

\section{Secondary Analysis: Adherence}

The secondary analysis examining comparisons that included a measure of adherence $(36 / 50,72 \%)$ failed to show a significant effect of gamification elements $(\beta=-1.93, \mathrm{SE}=2.28 ; \mathrm{P}=.40)$ on adherence rates. However, intervention duration was a significant predictor such that longer interventions were associated with higher adherence rates $(\beta=11.33, \mathrm{SE}=3.57$; $\mathrm{P}=.003)$. Similarly, when examining only the CBT-based mental health apps $(25 / 50,50 \%)$, there was no effect of gamification 
elements on adherence $(\beta=0.17, \mathrm{SE}=2.51 ; \mathrm{P}=.95)$, but intervention duration positively predicted adherence $(\beta=12.23$, $\mathrm{SE}=4.21 ; \mathrm{P}=.008)$.

\section{Funnel Plot Results}

Examination of the funnel plot of the posttreatment effect SEs indicated heteroscedasticity. The Egger test of asymmetry was significant $\left(\mathrm{Q}_{50}=214.46, \mathrm{P}<.001\right)$. A trim-and-fill analysis suggested a trending finding of three missing publications to the right, though this did not reach the level of statistical significance $(\beta=2.45, \mathrm{P}=.13)$. To be conservative, the pseudo-CIs in Figure 4 were adjusted per $\tau^{2}$, with trim-and-fill studies as white dots. Controlling for the violations of these assumptions, the overall random effects model was significant $(\beta=-0.26$, $\mathrm{SE}=0.06 ; \mathrm{P}<.001)$, indicating a significant improvement overall.

Figure 4. Funnel plot for all studies ( $\mathrm{n}=50$ comparisons) showing the heterogeneity for each.

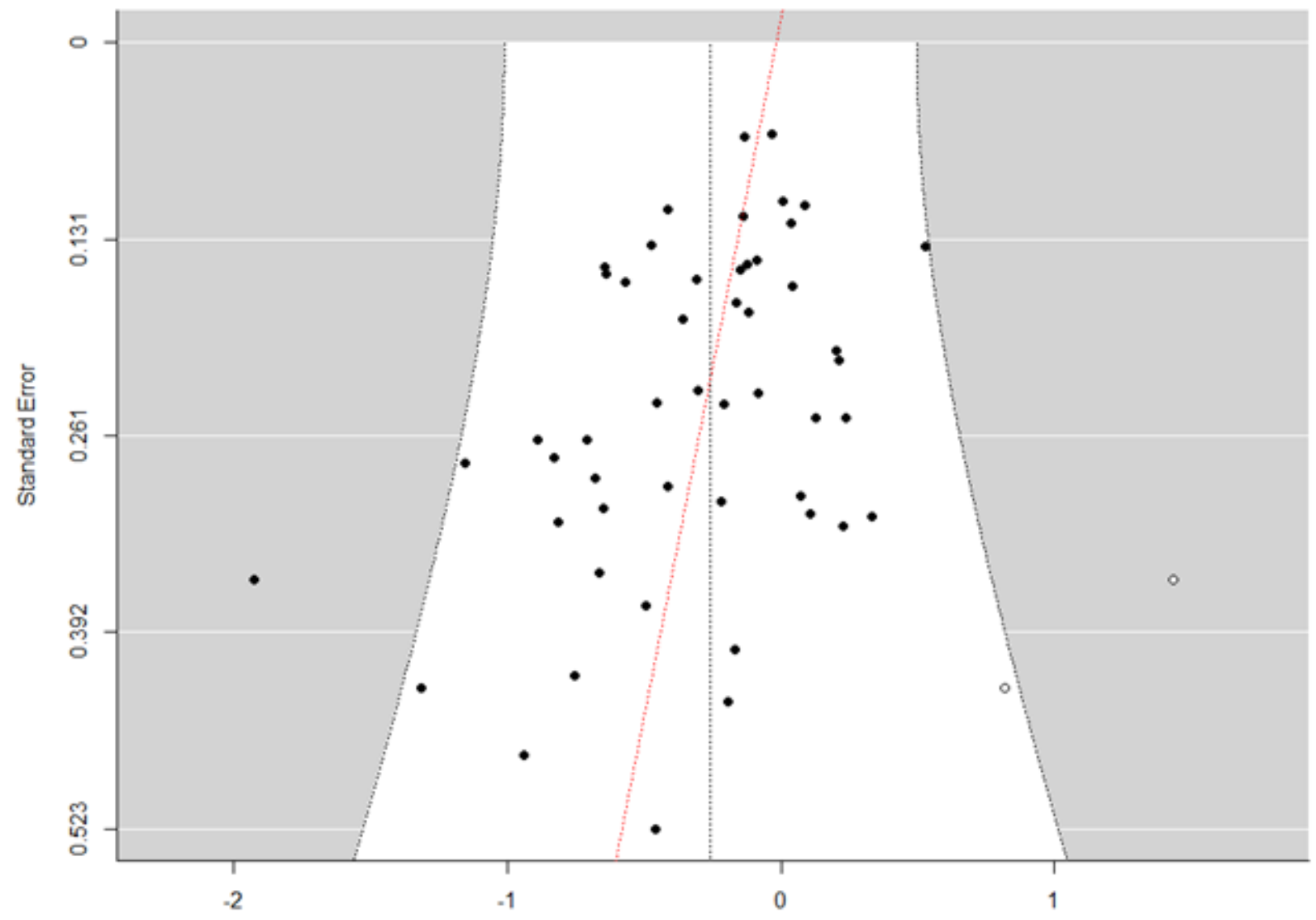

Standardized Mean Difference

\section{Discussion}

\section{Principal Findings}

This meta-analysis provides a comprehensive update about the effectiveness of mental health apps in reducing depressive symptoms, and it tests whether mental health apps with gamification elements are effective for reducing depressive symptoms. Results indicated that mental health apps are effective for reducing depressive symptoms, but gamification elements within mental health apps do not seem to reduce depressive symptoms or increase the adherence of using mental health apps.

Examination of mental health apps that exclusively employed computerized CBT (excluding mindfulness and ACT) similarly failed to show an effect of gamification on depressive symptom reduction. It should be noted that some of the included studies had a high risk of bias and, as such, the results should be interpreted with caution. Nevertheless, the evidence from this meta-analysis suggests that CBT effectively aids with the control, maintenance, and reduction of depressive symptoms, but gamification and reward elements embedded in mental health apps do not significantly alleviate such symptoms.

Consistent with prior systematic reviews and meta-analyses on digital interventions for depression, we found that mental health app interventions are moderately effective in reducing depressive symptoms compared to controls [26,37,38,41,89]. Effect sizes from these prior meta-analyses ranged from 0.33 to 0.58 , which is slightly higher than the small to moderate effect size observed in this meta-analysis. While this research provides strong consensus of a general positive effect of mental health apps on alleviating depressive symptoms, the specific elements that contribute to this effect remain largely elusive. Previous systematic reviews have demonstrated that guidance and support from a professional can augment the effectiveness of mental health app interventions $[37,105]$. Other work suggests that incorporating reminders into digital mental health interventions can promote engagement and adherence with the intervention, 
which may, in turn, enhance the intervention's therapeutic benefits [38]. However, the results of this meta-analysis did not show a significant relationship between gamification and adherence rates. Understanding how such features work together to mitigate depressive symptoms is critical for improving mental health app development.

One potential explanation of why gamification elements do not moderate depressive symptoms may be reward sensitivity. Depression generally has been associated with hyposensitivity to rewards, particularly among those with anhedonic symptoms [11-13,16,17]. This diminished reward-related neural activity may decrease motivation to obtain rewards or diminish the positive reward experience. While the UGM model proposes reward as a critical part of motivation to ensure engagement, it also suggests moderating effects, such as self-efficacy and locus of control. These variables have known negative relationships with depression [106,107] and may make gamification less effective. An alternative explanation for the results may be that gamification does not engender additive benefits. The included mental health apps all used strong, evidence-based therapeutic interventions, including CBT, ACT, and mindfulness. Based on the results of this meta-analysis, these interventions appear to be sufficient in mitigating depressive symptoms.

Overall, 30 studies in this meta-analysis showed a significant effect, while nine studies failed to produce significant reductions in depressive symptoms. In terms of gamification elements, four of the apps that were associated with nonsignificant findings included at least two elements of gamification: Kokoro, Headspace, MoodGYM, and Be Good to Yourself [50,52,59,67]. In contrast, two of these apps-Headspace and MoodGYM-were used in other studies, where they produced significant positive changes in depressive symptoms $[31,53,64,65,68,69]$. These mixed findings support the notion that while mental health apps may have a future in telemedicine and psychological settings $[89,108]$, more research is needed to understand which mental health app features are integral to improving mental health symptoms. From there, these facets can be properly implemented as a methodologically reliable therapeutic technique.

The push for the creation of efficient and scientifically supported mental health apps grows each year as technology becomes more ubiquitous [109]. These apps could aid therapists who are unable to accept any new clients and people who may not have access to psychological centers or counselors due to financial strains, location, or disabilities. This meta-analysis adds to the current literature by suggesting against overreliance on reward and gamification elements as major reducers of depressive symptoms. These elements may be beneficial in mental health apps, but no more so than other evidence-based therapeutic features. Many of the mental health apps currently available to the general public lack valid testing of their efficacy; thus, there is a strong need for rigorous evaluation of such apps on psychological outcomes. Indeed, in this meta-analysis, nearly half of the included studies incorporated gamification elements, yet the results suggest that such elements exert minimal therapeutic benefits. Significantly more research is needed to identify which specific mental health app features maximize therapeutic effects.

\section{Limitations}

This systematic review and meta-analysis had some limitations, which were largely related to inadequacies in the studies available for analyses. Results were calculated based on aggregated samples, which may have caused a certain level of ecological bias. Due to the disparate sample of apps, heterogeneity was detected in all primary analyses. However, heterogeneity was nearly identical to past research on this topic, and we took statistical efforts to minimize this impact [38]. In addition, the meta-analysis was not exclusive to individuals with clinical levels of depression, but all experiencing depressive symptoms. No data sets were consistently available across all studies to assess clinical depression diagnoses or psychiatric comorbidities. Consequently, the findings may not generalize to individuals with severe depression or individuals with other mental health conditions.

\section{Future Research Using Gamification Elements}

The main findings of this study were that mental health apps are effective for reducing depressive symptoms, but gamification elements within these mental health apps do not seem to affect depressive symptoms. It is possible that mental health apps with gamification elements may influence patients managing anxiety, stress, or other conditions where anhedonia is not present. Thus, gamification may not be a promising app feature for depressive symptoms but may hold promise for other mental health conditions. Future research should consider examining the effectiveness of mental health apps with gamification on other mental health conditions. While previous research has investigated the effectiveness of mental health apps on anxiety and life satisfaction [50,56], the effect of gamification elements on these psychological factors remains underexplored. Moreover, there is a need for additional research to better characterize the usability benefits and user preferences of mental health apps. If gamification within mental health apps is not effective for individuals experiencing depressive symptoms, then it is important to identify other potential features. Designing specific features that may motivate users with depression toward continued mental health app adherence could lead to beneficial outcomes.

\section{Conclusions}

Mental health apps have proven to be a useful tool in reducing depressive symptoms with or without the inclusion of gamification elements. These results demonstrate that although there is a significant improvement in using mental health apps overall, there is no evidence to suggest that gamification makes outcomes significantly better or worse. Additional elements, such as personalization, motivational reminders, social support, and usability, need to be investigated. Mental health apps may provide a readily available option for global psychological care; however, supplementary research is needed on their effectiveness before reliable implementation into the health care system can occur. 


\section{Conflicts of Interest}

None declared.

\section{Multimedia Appendix 1}

Search terms for the meta-analysis.

[DOCX File, $15 \mathrm{~KB}$-Multimedia Appendix 1]

\section{Multimedia Appendix 2}

Database screening tool.

[DOCX File, 15 KB-Multimedia Appendix 2]

\section{Multimedia Appendix 3}

Study demographics extracted from articles: sample, length, population, age, and gender.

[DOCX File, 24 KB-Multimedia Appendix 3]

\section{Multimedia Appendix 4}

Quality assessment screening.

[DOCX File , $21 \mathrm{~KB}-$ Multimedia Appendix 4]

\section{Multimedia Appendix 5}

Gamification screening for publications.

[DOCX File , 25 KB-Multimedia Appendix 5]

\section{Multimedia Appendix 6}

Sensitivity and supplemental analyses.

[DOCX File, 14 KB-Multimedia Appendix 6]

\section{Multimedia Appendix 7}

Sensitivity analysis for cognitive behavioral therapy (CBT)-only studies.

[DOCX File, 29 KB-Multimedia Appendix 7]

\section{References}

1. Major depression. National Institute of Mental Health. 2019. URL: https://www.nimh.nih.gov/health/statistics/ major-depression.html [accessed 2021-07-12]

2. National Collaborating Centre for Mental Health (UK). Depression: The Treatment and Management of Depression in Adults (Updated Edition). Leicester, UK: British Psychological Society; 2010.

3. Weir K. APA offers new guidance for treating depression. Monitor on Psychology, American Psychological Association. 2019 Sep 01. URL: https://www.apa.org/monitor/2019/09/ce-corner-depression [accessed 2021-07-15]

4. Cartwright C, Gibson K, Read J, Cowan O, Dehar T. Long-term antidepressant use: Patient perspectives of benefits and adverse effects. Patient Prefer Adherence 2016;10:1401-1407 [FREE Full text] [doi: 10.2147/PPA.S110632] [Medline: 27528803]

5. Stein-Shvachman I, Karpas DS, Werner P. Depression treatment non-adherence and its psychosocial predictors: Differences between young and older adults? Aging Dis 2013 Sep 20;4(6):329-336 [FREE Full text] [doi: 10.14336/AD.2013.0400329] [Medline: 24307966]

6. Wood P, Burwell J, Rawlett K. New study reveals lack of access as root cause for mental health crisis in America. National Council for Mental Wellbeing. 2018 Oct 10. URL: https://www.thenationalcouncil.org/press-releases/ new-study-reveals-lack-of-access-as- [accessed 2021-07-15]

7. Van Hees S, Siewe Fodjo JN, Wijtvliet V, Van den Bergh R, Faria de Moura Villela E, da Silva CF, et al. Access to healthcare and prevalence of anxiety and depression in persons with epilepsy during the COVID-19 pandemic: A multicountry online survey. Epilepsy Behav 2020 Nov;112:107350 [FREE Full text] [doi: 10.1016/j.yebeh.2020.107350] [Medline: $\underline{32920373]}$

8. Winerman L. By the numbers: The cost of treatment. Monitor on Psychology, American Psychological Association. 2017 Mar. URL: https://www.apa.org/monitor/2017/03/numbers [accessed 2021-07-15] 
9. Neary M, Schueller SM. State of the field of mental health apps. Cogn Behav Pract 2018 Nov;25(4):531-537 [FREE Full text] [doi: 10.1016/j.cbpra.2018.01.002] [Medline: 33100810]

10. Mobile fact sheet. Pew Research Center. Washington, DC: Pew Research Center; 2021 Apr 07. URL: https://www. pewresearch.org/internet/factsheet/mobile/ [accessed 2021-07-15]

11. Admon R, Pizzagalli DA. Dysfunctional reward processing in depression. Curr Opin Psychol 2015 Aug 01;4:114-118 [FREE Full text] [doi: 10.1016/j.copsyc.2014.12.011] [Medline: 26258159]

12. Chen C, Takahashi T, Nakagawa S, Inoue T, Kusumi I. Reinforcement learning in depression: A review of computational research. Neurosci Biobehav Rev 2015 Aug;55:247-267. [doi: 10.1016/j.neubiorev.2015.05.005] [Medline: 25979140]

13. Eshel N, Roiser JP. Reward and punishment processing in depression. Biol Psychiatry 2010 Jul 15;68(2):118-124. [doi: 10.1016/j.biopsych.2010.01.027] [Medline: 20303067]

14. Safra L, Chevallier C, Palminteri S. Depressive symptoms are associated with blunted reward learning in social contexts. PLoS Comput Biol 2019 Jul;15(7):e1007224 [FREE Full text] [doi: 10.1371/journal.pcbi.1007224] [Medline: 31356594]

15. Vrijen C, Ackermans MA, Bosma A, Kretschmer T. Reward responsiveness, optimism, and social and mental functioning in children aged 6-7: Protocol of a cross-sectional pilot study. JMIR Res Protoc 2020 Sep 24;9(9):e18902 [FREE Full text] [doi: 10.2196/18902] [Medline: $\underline{32969825]}$

16. Foti D, Hajcak G. Depression and reduced sensitivity to non-rewards versus rewards: Evidence from event-related potentials. Biol Psychol 2009 Apr;81(1):1-8. [doi: 10.1016/j.biopsycho.2008.12.004] [Medline: 19162124]

17. Yang X, Huang J, Zhu C, Wang Y, Cheung EFC, Chan RCK, et al. Motivational deficits in effort-based decision making in individuals with subsyndromal depression, first-episode and remitted depression patients. Psychiatry Res 2014 Dec 30;220(3):874-882. [doi: 10.1016/j.psychres.2014.08.056] [Medline: 25262638]

18. Liu W, Chan RCK, Wang L, Huang J, Cheung EFC, Gong Q, et al. Deficits in sustaining reward responses in subsyndromal and syndromal major depression. Prog Neuropsychopharmacol Biol Psychiatry 2011 Jun 01;35(4): 1045-1052. [doi: 10.1016/j.pnpbp.2011.02.018] [Medline: 21371518]

19. Blohm I, Leimeister JM. Gamification. Bus Inf Syst Eng 2013 Jun 14;5(4):275-278. [doi: 10.1007/s12599-013-0273-5]

20. King D, Greaves F, Exeter C, Darzi A. 'Gamification': Influencing health behaviours with games. J R Soc Med 2013 Mar;106(3):76-78 [FREE Full text] [doi: 10.1177/0141076813480996] [Medline: 23481424]

21. Lister C, West JH, Cannon B, Sax T, Brodegard D. Just a fad? Gamification in health and fitness apps. JMIR Serious Games 2014 Aug 04;2(2):e9 [FREE Full text] [doi: 10.2196/games.3413] [Medline: 25654660]

22. Schmidt-Kraepelin M, Toussaint PA, Thiebes S, Hamari J, Sunyaev A. Archetypes of gamification: Analysis of mHealth apps. JMIR Mhealth Uhealth 2020 Oct 19;8(10):e19280 [FREE Full text] [doi: 10.2196/19280] [Medline: $\underline{33074155]}$

23. Hamari J, Koivisto J, Sarsa H. Does gamification work? -- A literature review of empirical studies on gamification. In: Proceedings of the Annual Hawaii International Conference on System Sciences. 2014 Presented at: Annual Hawaii International Conference on System Sciences; January 6-9, 2014; Waikoloa, HI p. 3025-3034. [doi: 10.1109/hicss.2014.377]

24. Dykens I, Wetzel A, Dorton S, Batchelor E. Towards a unified model of gamification and motivation. In: Proceedings of the International Conference on Human-Computer Interaction. Cham, Switzerland: Springer International Publishing; 2021 Presented at: International Conference on Human-Computer Interaction; July 24-29, 2021; Virtual p. 53-70. [doi: 10.1007/978-3-030-77857-6_4]

25. Cole SW, Yoo DJ, Knutson B. Interactivity and reward-related neural activation during a serious videogame. PLoS One 2012;7(3):e33909 [FREE Full text] [doi: 10.1371/journal.pone.0033909] [Medline: 22442733]

26. Li J, Theng Y, Foo S. Game-based digital interventions for depression therapy: A systematic review and meta-analysis. Cyberpsychol Behav Soc Netw 2014 Aug;17(8):519-527 [FREE Full text] [doi: 10.1089/cyber.2013.0481] [Medline: 24810933]

27. Brandt LR, Hidalgo L, Diez-Canseco F, Araya R, Mohr DC, Menezes PR, et al. Addressing depression comorbid with diabetes or hypertension in resource-poor settings: A qualitative study about user perception of a nurse-supported smartphone app in Peru. JMIR Ment Health 2019 Jun 18;6(6):e11701 [FREE Full text] [doi: 10.2196/11701] [Medline: $\underline{31215511]}$

28. Menezes P, Quayle J, Garcia Claro H, da Silva S, Brandt LR, Diez-Canseco F, et al. Use of a mobile phone app to treat depression comorbid with hypertension or diabetes: A pilot study in Brazil and Peru. JMIR Ment Health 2019 Apr 26;6(4):e11698 [FREE Full text] [doi: 10.2196/11698] [Medline: 31025949]

29. Avalos LA, Aghaee S, Kurtovich E, Quesenberry C, Nkemere L, McGinnis MK, et al. A mobile health mindfulness intervention for women with moderate to moderately severe postpartum depressive symptoms: Feasibility study. JMIR Ment Health 2020 Nov 12;7(11):e17405 [FREE Full text] [doi: 10.2196/17405] [Medline: $\underline{33180028}$ ]

30. Firth J, Torous J, Nicholas J, Carney R, Rosenbaum S, Sarris J. Can smartphone mental health interventions reduce symptoms of anxiety? A meta-analysis of randomized controlled trials. J Affect Disord 2017 Aug 15;218:15-22 [FREE Full text] [doi: 10.1016/j.jad.2017.04.046] [Medline: 28456072]

31. Roepke AM, Jaffee SR, Riffle OM, McGonigal J, Broome R, Maxwell B. Randomized controlled trial of SuperBetter, a smartphone-based/internet-based self-help tool to reduce depressive symptoms. Games Health J 2015 Jun;4(3):235-246. [doi: 10.1089/g4h.2014.0046] [Medline: 26182069] 
32. Griffiths MD, Kuss DJ, Ortiz de Gortari AB. Videogames as therapy: An updated selective review of the medical and psychological literature. In: Alternative Pain Management: Solutions for Avoiding Prescription Drug Overuse. Hershey, PA: IGI Global; 2020:324-363.

33. Lau HM, Smit JH, Fleming TM, Riper H. Serious games for mental health: Are they accessible, feasible, and effective? A systematic review and meta-analysis. Front Psychiatry 2016;7:209 [FREE Full text] [doi: 10.3389/fpsyt.2016.00209] [Medline: 28149281]

34. Wang K, Varma DS, Prosperi M. A systematic review of the effectiveness of mobile apps for monitoring and management of mental health symptoms or disorders. J Psychiatr Res 2018 Dec;107:73-78. [doi: 10.1016/j.jpsychires.2018.10.006] [Medline: $\underline{30347316}$ ]

35. Fleming T, Dixon R, Frampton C, Merry S. A pragmatic randomized controlled trial of computerized CBT (SPARX) for symptoms of depression among adolescents excluded from mainstream education. Behav Cogn Psychother 2012 Oct;40(5):529-541. [doi: 10.1017/S1352465811000695] [Medline: 22137185]

36. Fulmer R, Joerin A, Gentile B, Lakerink L, Rauws M. Using psychological artificial intelligence (Tess) to relieve symptoms of depression and anxiety: Randomized controlled trial. JMIR Ment Health 2018 Dec 13;5(4):e64 [FREE Full text] [doi: 10.2196/mental.9782] [Medline: 30545815]

37. Weisel KK, Fuhrmann LM, Berking M, Baumeister H, Cuijpers P, Ebert DD. Standalone smartphone apps for mental health-a systematic review and meta-analysis. NPJ Digit Med 2019;2:118 [FREE Full text] [doi: 10.1038/s41746-019-0188-8] [Medline: $\underline{31815193}$ ]

38. Wahle F, Bollhalder L, Kowatsch T, Fleisch E. Toward the design of evidence-based mental health information systems for people with depression: A systematic literature review and meta-analysis. J Med Internet Res 2017 May 31;19(5):e191 [FREE Full text] [doi: 10.2196/jmir.7381] [Medline: 28566267]

39. Lorenz RC, Gleich T, Gallinat J, Kühn S. Video game training and the reward system. Front Hum Neurosci 2015;9:40 [FREE Full text] [doi: 10.3389/fnhum.2015.00040] [Medline: 25698962]

40. Vallury KD, Jones M, Oosterbroek C. Computerized cognitive behavior therapy for anxiety and depression in rural areas: A systematic review. J Med Internet Res 2015 Jun 05;17(6):e139 [FREE Full text] [doi: 10.2196/jmir.4145] [Medline: 26048193]

41. Wright JH, Owen JJ, Richards D, Eells TD, Richardson T, Brown GK, et al. Computer-assisted cognitive-behavior therapy for depression: A systematic review and meta-analysis. J Clin Psychiatry 2019 Mar 19;80(2):e1-e14 [FREE Full text] [doi: 10.4088/JCP.18r12188] [Medline: $\underline{\text { 30900849] }}$

42. Lukas CA, Eskofier B, Berking M. A gamified smartphone-based intervention for depression: Randomized controlled pilot trial. JMIR Ment Health 2021 Jul 20;8(7):e16643 [FREE Full text] [doi: 10.2196/16643] [Medline: 34283037]

43. Dias LPS, Barbosa JLV, Vianna HD. Gamification and serious games in depression care: A systematic mapping study. Telematics Inform 2018 Apr;35(1):213-224. [doi: 10.1016/j.tele.2017.11.002]

44. Christie GI, Shepherd M, Merry SN, Hopkins S, Knightly S, Stasiak K. Gamifying CBT to deliver emotional health treatment to young people on smartphones. Internet Interv 2019 Dec;18:100286 [FREE Full text] [doi: 10.1016/j.invent.2019.100286] [Medline: $\underline{\text { 31890633] }}$

45. Russoniello C, O'Brien K, Parks J. The effectiveness of casual video games in improving mood and decreasing stress. J CyberTherapy Rehabil 2009;2(1):53-66 [FREE Full text]

46. Liberati A, Altman DG, Tetzlaff J, Mulrow C, Gøtzsche PC, Ioannidis JPA, et al. The PRISMA statement for reporting systematic reviews and meta-analyses of studies that evaluate health care interventions: Explanation and elaboration. J Clin Epidemiol 2009 Oct;62(10):e1-e34 [FREE Full text] [doi: 10.1016/j.jclinepi.2009.06.006] [Medline: 19631507]

47. Six S, Byrne KA. Rewards in mental health applications for aiding depression: A meta-analysis. Open Science Framework. Charlottesville, VA: Center for Open Science; 2021 May 27. URL: https://osf.io/ypm4x/ [accessed 2021-11-22]

48. Higgins JPT, Altman DG, Gøtzsche PC, Jüni P, Moher D, Oxman AD, Cochrane Bias Methods Group, Cochrane Statistical Methods Group. The Cochrane Collaboration's tool for assessing risk of bias in randomised trials. BMJ 2011 Oct 18;343:d5928 [FREE Full text] [doi: 10.1136/bmj.d5928] [Medline: 22008217]

49. Ha SW, Kim J. Designing a scalable, accessible, and effective mobile app based solution for common mental health problems. Int J Hum Comput Interact 2020 Apr 26;36(14):1354-1367. [doi: 10.1080/10447318.2020.1750792]

50. Twomey C, O'Reilly G, Byrne M, Bury M, White A, Kissane S, et al. A randomized controlled trial of the computerized CBT programme, MoodGYM, for public mental health service users waiting for interventions. Br J Clin Psychol 2014 Nov;53(4):433-450. [doi: 10.1111/bjc.12055] [Medline: 24831119]

51. Collins S, Byrne M, Hawe J, O'Reilly G. Evaluation of a computerized cognitive behavioural therapy programme, MindWise (2.0), for adults with mild-to-moderate depression and anxiety. Br J Clin Psychol 2018 Jun;57(2):255-269. [doi: 10.1111/bjc.12165] [Medline: 29197102]

52. Mantani A, Kato T, Furukawa TA, Horikoshi M, Imai H, Hiroe T, et al. Smartphone cognitive behavioral therapy as an adjunct to pharmacotherapy for refractory depression: Randomized controlled trial. J Med Internet Res 2017 Nov 03;19(11):e373 [FREE Full text] [doi: 10.2196/jmir.8602] [Medline: 29101095] 
53. Fish MT, Saul AD. The gamification of meditation: A randomized-controlled study of a prescribed mobile mindfulness meditation application in reducing college students' depression. Simul Gaming 2019 Jun 04;50(4):419-435. [doi: $10.1177 / 1046878119851821]$

54. Bakker D, Kazantzis N, Rickwood D, Rickard N. A randomized controlled trial of three smartphone apps for enhancing public mental health. Behav Res Ther 2018 Oct;109:75-83. [doi: 10.1016/j.brat.2018.08.003] [Medline: $\underline{30125790]}$

55. Richards D, Enrique A, Eilert N, Franklin M, Palacios J, Duffy D, et al. A pragmatic randomized waitlist-controlled effectiveness and cost-effectiveness trial of digital interventions for depression and anxiety. NPJ Digit Med 2020;3:85 [FREE Full text] [doi: 10.1038/s41746-020-0293-8] [Medline: $\underline{\text { 32566763] }}$

56. Howells A, Ivtzan I, Eiroa-Orosa FJ. Putting the 'app' in happiness: A randomised controlled trial of a smartphone-based mindfulness intervention to enhance wellbeing. J Happiness Stud 2014 Oct 29;17(1):163-185. [doi:

10.1007/s10902-014-9589-1]

57. Botella C, Mira A, Moragrega I, García-Palacios A, Bretón-López J, Castilla D, et al. An internet-based program for depression using activity and physiological sensors: Efficacy, expectations, satisfaction, and ease of use. Neuropsychiatr Dis Treat 2016;12:393-406 [FREE Full text] [doi: 10.2147/NDT.S93315] [Medline: 27042067]

58. Krafft J, Potts S, Schoendorff B, Levin ME. Arandomized controlled trial of multiple versions of an acceptance and commitment therapy matrix app for well-being. Behav Modif 2019 Mar;43(2):246-272. [doi: 10.1177/0145445517748561] [Medline: 29262693]

59. Lüdtke T, Pult LK, Schröder J, Moritz S, Bücker L. A randomized controlled trial on a smartphone self-help application (Be Good to Yourself) to reduce depressive symptoms. Psychiatry Res 2018 Nov;269:753-762. [doi: 10.1016/j.psychres.2018.08.113] [Medline: $\underline{30273901]}$

60. Lokman S, Leone SS, Sommers-Spijkerman M, van der Poel A, Smit F, Boon B. Complaint-directed mini-interventions for depressive complaints: A randomized controlled trial of unguided web-based self-help interventions. J Med Internet Res 2017 Jan 04;19(1):e4 [FREE Full text] [doi: 10.2196/jmir.6581] [Medline: 28052840]

61. Moberg C, Niles A, Beermann D. Guided self-help works: Randomized waitlist controlled trial of Pacifica, a mobile app integrating cognitive behavioral therapy and mindfulness for stress, anxiety, and depression. J Med Internet Res 2019 Jun 08;21(6):e12556 [FREE Full text] [doi: 10.2196/12556] [Medline: 31199319]

62. de Graaf LE, Gerhards SAH, Arntz A, Riper H, Metsemakers JFM, Evers SMAA, et al. Clinical effectiveness of online computerised cognitive-behavioural therapy without support for depression in primary care: Randomised trial. Br J Psychiatry 2009 Jul;195(1):73-80. [doi: 10.1192/bjp.bp.108.054429] [Medline: 19567900]

63. Gilbody S, Littlewood E, Hewitt C, Brierley G, Tharmanathan P, Araya R, REEACT Team. Computerised cognitive behaviour therapy (cCBT) as treatment for depression in primary care (REEACT trial): Large scale pragmatic randomised controlled trial. BMJ 2015 Nov 11;351:h5627 [FREE Full text] [doi: 10.1136/bmj.h5627] [Medline: 26559241]

64. Löbner M, Pabst A, Stein J, Dorow M, Matschinger H, Luppa M, et al. Computerized cognitive behavior therapy for patients with mild to moderately severe depression in primary care: A pragmatic cluster randomized controlled trial (@ktiv). J Affect Disord 2018 Oct 01;238:317-326. [doi: 10.1016/j.jad.2018.06.008] [Medline: 29902736]

65. Sethi S. Treating youth depression and anxiety: A randomised controlled trial examining the efficacy of computerised versus face - to - face cognitive behaviour therapy. Aust Psychol 2020 Nov 12;48(4):249-257. [doi: 10.1111/ap.12006]

66. Dahne J, Collado A, Lejuez CW, Risco CM, Diaz VA, Coles L, et al. Pilot randomized controlled trial of a Spanish-language behavioral activation mobile app (¡Aptívate!) for the treatment of depressive symptoms among United States Latinx adults with limited English proficiency. J Affect Disord 2019 May 01;250:210-217 [FREE Full text] [doi: 10.1016/j.jad.2019.03.009] [Medline: $\underline{\text { 30870770] }}$

67. Bosso KB. The Effects of Mindfulness Training on BDNF Levels, Depression, Anxiety, and Stress Levels of College Students [undergraduate thesis]. Boca Raton, FL: Florida Atlantic University; 2020 May. URL: http://fau.digital.flvc.org/ islandora/object/fau\%3A42592 [accessed 2021-11-22]

68. Bostock S, Crosswell AD, Prather AA, Steptoe A. Mindfulness on-the-go: Effects of a mindfulness meditation app on work stress and well-being. J Occup Health Psychol 2019 Feb;24(1):127-138 [FREE Full text] [doi: 10.1037/ocp0000118] [Medline: 29723001]

69. Flett JAM, Hayne H, Riordan BC, Thompson LM, Conner TS. Mobile mindfulness meditation: A randomised controlled trial of the effect of two popular apps on mental health. Mindfulness 2018 Oct 31;10(5):863-876. [doi: 10.1007/s12671-018-1050-9]

70. McCloud T, Jones R, Lewis G, Bell V, Tsakanikos E. Effectiveness of a mobile app intervention for anxiety and depression symptoms in university students: Randomized controlled trial. JMIR Mhealth Uhealth 2020 Jul 31;8(7):e15418 [FREE Full text] [doi: $\underline{10.2196 / 15418}$ ] [Medline: $\underline{32735221]}$

71. Kladnitski N, Smith J, Uppal S, James MA, Allen AR, Andrews G, et al. Transdiagnostic internet-delivered CBT and mindfulness-based treatment for depression and anxiety: A randomised controlled trial. Internet Interv 2020 Apr;20:100310 [FREE Full text] [doi: 10.1016/j.invent.2020.100310] [Medline: 32140427]

72. Hur J, Kim B, Park D, Choi S. A scenario-based cognitive behavioral therapy mobile app to reduce dysfunctional beliefs in individuals with depression: A randomized controlled trial. Telemed J E Health 2018 Sep;24(9):710-716. [doi: 10.1089/tmj.2017.0214] [Medline: 29323626] 
73. Fuller-Tyszkiewicz M, Richardson B, Little K, Teague S, Hartley-Clark L, Capic T, et al. Efficacy of a smartphone app intervention for reducing caregiver stress: Randomized controlled trial. JMIR Ment Health 2020 Jul 24;7(7):e17541 [FREE Full text] [doi: $10.2196 / 17541]$ [Medline: $\underline{\text { 32706716] }}$

74. Tighe J, Shand F, Ridani R, Mackinnon A, De La Mata N, Christensen H. Ibobbly mobile health intervention for suicide prevention in Australian Indigenous youth: A pilot randomised controlled trial. BMJ Open 2017 Jan 27;7(1):e013518 [FREE Full text] [doi: 10.1136/bmjopen-2016-013518] [Medline: 28132007]

75. Levin ME, Hicks ET, Krafft J. J Am Coll Health 2020 Mar 09:1-9. [doi: 10.1080/07448481.2020.1728281] [Medline: 32150519]

76. Schure MB, Lindow JC, Greist JH, Nakonezny PA, Bailey SJ, Bryan WL, et al. Use of a fully automated internet-based cognitive behavior therapy intervention in a community population of adults with depression symptoms: Randomized controlled trial. J Med Internet Res 2019 Nov 18;21(11):e14754 [FREE Full text] [doi: 10.2196/14754] [Medline: 31738173]

77. Dahne J, Lejuez CW, Diaz VA, Player MS, Kustanowitz J, Felton JW, et al. Pilot randomized trial of a self-help behavioral activation mobile app for utilization in primary care. Behav Ther 2019 Jul;50(4):817-827 [FREE Full text] [doi: 10.1016/j.beth.2018.12.003] [Medline: $\underline{31208690]}$

78. Deady M, Glozier N, Calvo R, Johnston D, Mackinnon A, Milne D, et al. Preventing depression using a smartphone app: A randomized controlled trial. Psychol Med 2020 Jul 06:1-10. [doi: 10.1017/S0033291720002081] [Medline: 32624013]

79. Lintvedt OK, Griffiths KM, Sørensen K, Østvik AR, Wang CEA, Eisemann M, et al. Evaluating the effectiveness and efficacy of unguided internet-based self-help intervention for the prevention of depression: A randomized controlled trial. Clin Psychol Psychother 2013;20(1):10-27. [doi: 10.1002/cpp.770] [Medline: 21887811]

80. Birney AJ, Gunn R, Russell JK, Ary DV. MoodHacker mobile web app with email for adults to self-manage mild-to-moderate depression: Randomized controlled trial. JMIR Mhealth Uhealth 2016 Jan 26;4(1):e8 [FREE Full text] [doi: 10.2196/mhealth.4231] [Medline: 26813737]

81. Choi I, Zou J, Titov N, Dear BF, Li S, Johnston L, et al. Culturally attuned internet treatment for depression amongst Chinese Australians: A randomised controlled trial. J Affect Disord 2012 Feb;136(3):459-468. [doi: 10.1016/j.jad.2011.11.003] [Medline: 22177742]

82. Montero-Marín J, Araya R, Pérez-Yus MC, Mayoral F, Gili M, Botella C, et al. An internet-based intervention for depression in primary care in Spain: A randomized controlled trial. J Med Internet Res 2016 Aug 26;18(8):e231 [FRE Full text] [doi: 10.2196/jmir.5695] [Medline: 27565118]

83. Richards D, Timulak L, O'Brien E, Hayes C, Vigano N, Sharry J, et al. A randomized controlled trial of an internet-delivered treatment: Its potential as a low-intensity community intervention for adults with symptoms of depression. Behav Res Ther 2015 Dec;75:20-31. [doi: 10.1016/j.brat.2015.10.005] [Medline: 26523885]

84. Rollman BL, Herbeck Belnap B, Abebe KZ, Spring MB, Rotondi AJ, Rothenberger SD, et al. Effectiveness of online collaborative care for treating mood and anxiety disorders in primary care: A randomized clinical trial. JAMA Psychiatry 2018 Jan 01;75(1):56-64 [FREE Full text] [doi: 10.1001/jamapsychiatry.2017.3379] [Medline: 29117275]

85. Berger T, Hämmerli K, Gubser N, Andersson G, Caspar F. Internet-based treatment of depression: A randomized controlled trial comparing guided with unguided self-help. Cogn Behav Ther 2011;40(4):251-266. [doi: 10.1080/16506073.2011.616531] [Medline: 22060248]

86. Johnson D, Deterding S, Kuhn K, Staneva A, Stoyanov S, Hides L. Gamification for health and wellbeing: A systematic review of the literature. Internet Interv 2016 Nov;6:89-106 [FREE Full text] [doi: 10.1016/j.invent.2016.10.002] [Medline: 30135818]

87. Esteves J, Valogianni K, Greenhill A. Online social games: The effect of social comparison elements on continuance behaviour. Inf Manag 2021 Jun;58(4):103452. [doi: 10.1016/j.im.2021.103452]

88. Lian S, Sun X, Niu G, Zhou Z. Upward social comparison on SNS and depression: A moderated mediation model and gender difference. Acta Psychol Sinica 2017;49(7):941-952. [doi: 10.3724/sp.j.1041.2017.00941]

89. Donker T, Petrie K, Proudfoot J, Clarke J, Birch M, Christensen H. Smartphones for smarter delivery of mental health programs: A systematic review. J Med Internet Res 2013 Nov 15;15(11):e247 [FREE Full text] [doi: 10.2196/jmir.2791] [Medline: 24240579]

90. Kroenke K, Spitzer RL, Williams JB. The PHQ-9: Validity of a brief depression severity measure. J Gen Intern Med 2001 Sep;16(9):606-613 [FREE Full text] [doi: 10.1046/j.1525-1497.2001.016009606.x] [Medline: 11556941]

91. Beck AT, Brown GK, Steer RA. Beck Depression Inventory-II (BDI-II). Pearson. 1996. URL: https://www.pearsonclinical.ca/ store/caassessments/en/Store/Professional-Assessments/Personality-\%26-Biopsychosocial/Brief/ Beck-Depression-Inventory-II/p/P100008037.html [accessed 2021-11-22]

92. Eaton W, Smith C, Ybarra M, Muntaner C, Tien A. Center for Epidemiologic Studies Depression Scale: Review and revision (CESD and CESD-R). In: Maruish ME, editor. The Use of Psychological Testing for Treatment Planning and Outcomes Assessment. 3rd edition. Volume 3: Instruments for Adults. Mahwah, NJ: Lawrence Erlbaum Associates; 2004:363-377.

93. Lovibond PF, Lovibond SH. The structure of negative emotional states: Comparison of the Depression Anxiety Stress Scales (DASS) with the Beck Depression and Anxiety Inventories. Behav Res Ther 1995 Mar;33(3):335-343. [doi: 10.1016/0005-7967(94)00075-u] [Medline: 7726811] 
94. Zigmond AS, Snaith RP. The Hospital Anxiety and Depression Scale. Acta Psychiatr Scand 1983 Jun;67(6):361-370. [doi: 10.1111/j.1600-0447.1983.tb09716.x] [Medline: $\underline{6880820}$ ]

95. Rush AJ, Gullion CM, Basco MR, Jarrett RB, Trivedi MH. The Inventory of Depressive Symptomatology (IDS): Psychometric properties. Psychol Med 1996 May;26(3):477-486. [doi: 10.1017/s0033291700035558] [Medline: $\underline{\text { 8733206] }}$

96. Locke BD, McAleavey AA, Zhao Y, Lei P, Hayes JA, Castonguay LG, et al. Development and initial validation of the Counseling Center Assessment of Psychological Symptoms-34. Meas Eval Couns Dev 2017 Mar 10;45(3):151-169. [doi: 10.1177/0748175611432642]

97. Borenstein M, Hedges LV, Higgins JPT, Rothstein HR. Introduction to Meta-Analysis. Chichester, UK: John Wiley \& Sons, Ltd; 2009.

98. Lakens D. Calculating and reporting effect sizes to facilitate cumulative science: A practical primer for t-tests and ANOVAs. Front Psychol 2013 Nov 26;4:863 [FREE Full text] [doi: 10.3389/fpsyg.2013.00863] [Medline: 24324449]

99. Hedges LV, Olkin I. Statistical Methods for Meta-Analysis. Orlando, FL: Academic Press, Inc; 1985.

100. Cohen J. A power primer. Psychol Bull 1992 Jul;112(1):155-159. [doi: 10.1037//0033-2909.112.1.155] [Medline: 19565683]

101. Higgins JPT, Thompson SG. Quantifying heterogeneity in a meta-analysis. Stat Med 2002 Jun 15;21(11):1539-1558. [doi: 10.1002/sim.1186] [Medline: 12111919]

102. Higgins JPT, Thomas J, Chandler J, Cumpston M, Li T, Page MJ, et al, editors. Cochrane Handbook for Systematic Reviews of Interventions. 2nd edition. Hoboken, NJ: John Wiley \& Sons, Ltd; 2019.

103. Egger M, Davey Smith G, Schneider M, Minder C. Bias in meta-analysis detected by a simple, graphical test. BMJ 1997 Sep 13;315(7109):629-634 [FREE Full text] [doi: 10.1136/bmj.315.7109.629] [Medline: 9310563]

104. Duval S, Tweedie R. Trim and fill: A simple funnel-plot-based method of testing and adjusting for publication bias in meta-analysis. Biometrics 2000 Jun;56(2):455-463. [doi: 10.1111/j.0006-341x.2000.00455.x] [Medline: 10877304]

105. Baumeister H, Reichler L, Munzinger M, Lin J. The impact of guidance on internet-based mental health interventions A systematic review. Internet Interv 2014 Oct;1(4):205-215. [doi: 10.1016/j.invent.2014.08.003]

106. Benassi VA, Sweeney PD, Dufour CL. Is there a relation between locus of control orientation and depression? J Abnorm Psychol 1988 Aug;97(3):357-367. [doi: 10.1037//0021-843x.97.3.357] [Medline: 3057032]

107. Bandura A. Self-efficacy mechanism in human agency. Am Psychologist 1982;37(2):122-147. [doi: 10.1037/0003-066x.37.2.122]

108. Hategan A, Giroux C, Bourgeois JA. Digital technology adoption in psychiatric care: An overview of the contemporary shift from technology to opportunity. J Technol Behav Sci 2019 Mar 7;4(3):171-177. [doi: 10.1007/s41347-019-00086-x]

109. Czeisler MÉ, Lane RI, Petrosky E, Wiley JF, Christensen A, Njai R, et al. Mental health, substance use, and suicidal ideation during the COVID-19 pandemic - United States, June 24-30, 2020. MMWR Morb Mortal Wkly Rep 2020 Aug 14;69(32):1049-1057 [FREE Full text] [doi: 10.15585/mmwr.mm6932a1] [Medline: 32790653]

\author{
Abbreviations \\ ACT: acceptance and commitment therapy \\ BA: behavioral activation \\ BDI-II: Beck Depression Inventory-II \\ CBT: cognitive behavioral therapy \\ CCAPS-34: Counseling Center Assessment of Psychological Symptoms-34 \\ CES-D: Center for Epidemiological Studies Depression Scale \\ DASS-21: 21-item Depression, Anxiety, and Stress Scale \\ HADS: Hospital Anxiety and Depression Scale \\ IDS-SR: Inventory of Depressive Symptomatology Self-Report \\ PHQ-9: 9-item Patient Health Questionnaire \\ PRISMA: Preferred Reporting Items for Systematic Reviews and Meta-Analyses \\ PROMIS: Patient-Reported Outcomes Measurement Information System \\ RCT: randomized controlled trial \\ UGM: Unified Gamification and Motivation
}


Edited by J Torous, G Eysenbach; submitted 24.07.21; peer-reviewed by T Baranowski, R Nogueira-Arjona, M Schure; comments to author 15.08.21; revised version received 10.10.21; accepted 11.10.21; published 29.11.21

Please cite as:

Six SG, Byrne KA, Tibbett TP, Pericot-Valverde I

Examining the Effectiveness of Gamification in Mental Health Apps for Depression: Systematic Review and Meta-analysis JMIR Ment Health 2021;8(11):e32199

URL: https://mental.jmir.org/2021/11/e32199

doi: $10.2196 / 32199$

PMID:

(CStephanie G Six, Kaileigh A Byrne, Thomas P Tibbett, Irene Pericot-Valverde. Originally published in JMIR Mental Health (https://mental.jmir.org), 29.11.2021. This is an open-access article distributed under the terms of the Creative Commons Attribution License (https://creativecommons.org/licenses/by/4.0/), which permits unrestricted use, distribution, and reproduction in any medium, provided the original work, first published in JMIR Mental Health, is properly cited. The complete bibliographic information, a link to the original publication on https://mental.jmir.org/, as well as this copyright and license information must be included. 